Biosight 2020; 01(02): 11-15

\title{
Genetic Variations of Brain Derived Neurotropic Factor Gene With Premenstrual Syndrome Among Pakistani Menarcheal Girls: A Pilot Study
}

\author{
Mehir un Nisa Iqbal, Fatima Noor, Taseer Ahmed Khan \\ Department of Physiology, University of Karachi, Karachi, Pakistan
}

Received: September 16, 2020

Accepted: October 20, 2020

\begin{abstract}
The premenstrual syndrome (PMS) comprises various physical and emotional symptoms which are associated with the menstrual cycle. The emotional changes might be due to the variation in the levels of BDNF especially lower levels of plasma BDNF may be present at the luteal phase of menstrual cycle. To date, no data were present to associate the link between BDNF gene polymorphism and PMS among young Menarcheal females. So, the goal of this investigation is to find out the possible relationship between BDNF gene polymorphism and PMS among young Menarcheal females of Pakistan. A total of 92 menarcheal girls with age range of 11-14yrs met the inclusion criteria. All participants were screened for the depression and PMS using Zung's depression scale/ Diagnostic and Statistical Manual of Mental Disorders-IV (DSM IV) criteria and world health organization (WHO) criteria for PMS respectively. Genomic DNA was extracted from oral samples by Salting out method and BDNF genotyping was done using PCR-RFLP analysis. Results showed no significant association $\left(\chi^{2}=1.685\right.$, $p$-value $\left.=0.431\right)$ was observed between BDNF genotyping and PMS among menarcheal girls. BDNF (rs6265) AA and GA genotypes did not show significant association with the risk of PMS. Hence, it was concluded that BDNF gene polymorphism may not be associated with the PMS among Pakistani Menarcheal girls.
\end{abstract}

Keywords: Premenstrual syndrome; Brain-derived neurotrophic factor; rs6265; menarche; Depression.

Corresponding Author: Mehir un Nisa Iqbal, Department of Physiology, University of Karachi University road, Karachi, Pakistan Cell: 0092-345-3133309, Email: mehirunisa@ uok.edu.pk

\section{Introduction:}

Premenstrual syndromes (PMS) is typically present in reproductive age women [1] and can be defined as a cluster of emotional and physical symptoms occur shortly before each menstrual cycle and resolves at the beginning of menstruation [2]. In women, PMS is the main source to cause considerable physical and psychological distress during their reproductive years. Although the cause of this distress during menstrual cycle is unclear. The prevalence rate of PMS in northern Ethiopia [3], Jordanians [4] Iran and France [5] was 37.0\%, 80.2\% and 98\% and 12\% respectively whereas in Pakistan 53\% of females have PMS permitting to ICD-10 (International Statistical Classification of Diseases and Related Health Problems-10) criteria [6]. PMS includes many emotional and behavioral symptoms like nervousness, sadness, crying spells, mood swings, irritability, changes in appetite, difficulty in concentration, sleeplessness, mood swings, social withdrawal and some physical signs and symptoms like body aches, headache, tiredness, weight gain, abdominal bloating, and breast tenderness [7,8]. To date, more than 150 symptoms of PMS have been identified in which mood swings and depressive symptoms are prevalent. The most severe form of PMS is premenstrual dysphoric disorder (PMDD), a combination of many psychological and somatic symptoms prompting in the luteal phase resulting in the menstruation [9].

PMS can be caused by changes in the ovarian steroids and other cyclical hormones which directly intricate in the regulation of depressive mood and cognitive functions and can influence the expression of BDNF [10]. In the luteal phase, the expression of BDNF was lower may involve in the alteration of hormone response and may develop PMS related symptoms [10]. In another study, the increased serum BDNF level was also found in the luteal phase among participants with PMDD which may reveal a compensatory mechanism resulting in the consequent improvement of PMDD in the follicular phase of menstrual cycle [9].

The gene for BDNF resided at chromosome no. 11p14.1 belongs to neurotropin family of growth factors and has high affinity towards tyrosine kinase B (TrkB) receptors generally present all over the central nervous system [11]. Val66Met is the polymorphism in the BDNF gene located at position 196 guanine to adenine (G/A) results in the substituted by of Val to Met at codon 66 of Pro-BDNF [12] a highly unstable region which constitutes 110 amino acid [13]. The Met allele reduces BDNF activity and leads to depressive life events [14]. The Val to Met substitution affects the activity of brain, alter the mood behavior and lead to the development of depression and anxiety [15]. It was found previously that BDNF gene polymorphism may be responsible for the development of depression when human BDNF polymorphic gene was inserted in female mice anxiety or depressive behaviors increased during the estrous cycle with decline estrogen levels [12]. It was also documented that the frequency of $\mathrm{G}$ allele (recessive homozygotes) was higher among PMDD in human population [16]. However, the association between BDNF gene polymorphism and PMS among menarcheal girls is not clear yet. So, the present investigation is the first of its kind to found the potential connection between the BDNF gene variant and PMS among menarcheal girls. 
Biosight 2020; 01(02): 11-15

\section{Materials and Methods}

Study participants

This study is based on schoole aged girls consisting of 92 participants (40 PMS cases and 52 healthy controls) recruited from different schools of Karachi, Pakistan from May-June 2014 with a mean age of 14 \pm 1 years and had signed informed written consent form. Sample size was calculated using online calculator OpenEpi (https: //www.openepi.com/SampleSize/SSCC.htm). All participants were screened for the depression using Zung's depression scale [17] and DSMIV (Diagnostic and Statistical Manual of Mental Disorders IV) criteria. PMS was identified according to the World Health Organization (WHO) criteria for diagnosing PMS. In this way, 40 PMS and 52 Non PMS subjects were recruited. This study was conducted in accordance with the Helsinki declaration and approved by the Board of Advance Studies and Research, University of Karachi (01199/2010). All girls who were less than 11yrs and more than $16 y r s$, prepubertal and post-menarcheal girls and diseased females are excluded from this study.

\section{Demographics}

Information such as age, socio-economic status, life style, Basal metabolic index (BMI), waist to hip ratio (WHR) and dietary profile was obtained using questionnaire. Information regarding menstrual history i.e. menarcheal age, the regularity of cycles, length of cycle, and physical manifestations during menstruation was also collected.

\section{DNA isolation}

Saliva samples of all participants were collected into $1.5 \mathrm{ml}$ of eppendorf tube and genomic DNA was extracted using standard Salting out method.

\section{Genotyping of BDNF (Val66Met, rs6265) polymorphism}

The BDNF gene was amplified by PCR thermal cycler (Veriti, Applied Biosystem, USA) using $4 \mu 1$ DNA, $10 \mu 1$ master mix (2X) (Fementas, USA), $0.5 \mu 1$ forward primer (5'-ACTCTGGAGAGCGTGAATGG-3') and reverse primers (5'-ACTACTGAGCATCACCCTGGA-3') (Integrated DNA Technologies, Inc. IDT, Coralville, Iowa) each (10 pmole) and $5 \mu \mathrm{l} \mathrm{DNA/RNA} \mathrm{free} \mathrm{water} \mathrm{in} \mathrm{total} 20 \mu \mathrm{l}$ volume. The temperature profile was $95^{\circ} \mathrm{C}(2 \mathrm{mins}), 40$ cycles of $95^{\circ} \mathrm{C}(30$ $\mathrm{sec}), 62{ }^{\circ} \mathrm{C}(30 \mathrm{sec}), 72{ }^{\circ} \mathrm{C}(30 \mathrm{sec})$ and final extension $72^{\circ} \mathrm{C}(7 \mathrm{mins})$. The amplified $(171 \mathrm{bp})$ products were then electrophoresed (80 volts) in $1.5 \%$ agarose gel having $0.45 \mathrm{~g}$ of agarose in $30 \mathrm{ml}$ of $0.5 \mathrm{X}$ TBE with $0.5 \mu \mathrm{g} / \mathrm{ml} \mathrm{of} \mathrm{EtBr}$ (ethidium bromide) seen under the electrophoretic amplified products using ChemiDoc-It2 (UVP, UK) Vision works LS software (version 7.1).

RELP was carried out by adding $0.5 \mu \mathrm{l}$ (5 units) of Eco72I (Fermentas, USA) restriction enzyme, 1ul buffer, 5ul PCR products and 3.5ul nuclease free water. The digested fragments of BDNF were electophoretically ( 80 volts) run on $3 \%$ of agarose gel and visualized under the same GelDoc with the same condition. The digested fragments were identified using $50 \mathrm{bp}$ ladder (Thermo scientific, USA). The undigested BDNF products were defined as homozygous dominant having A allele $(171 \mathrm{bp})$ in which restriction site was absent whereas two digested products were heterozygous and homozygous recessive with $171,92,72 \mathrm{bp}$ and $92,72 \mathrm{bp}$ ( $\mathrm{G}$ allele) respectively in which restriction sites was present.

\section{Analysis of data}

Any deviation of allele frequencies from predicted was calculated using Hardy-Weinberg equilibrium (HWE). The association between BDNF polymorphism and PMS was evaluated using Pearson Chi $\left(\chi^{2}\right)$ square test among menarcheal girls. Odds ratios (ORs) along with 95\% confidence intervals (CIs) via binary logistic regression analysis were used to find out the risk of PMS associated with BDNF genotype. All analyses were executed on SPSS 22 and all values were considered significant at $\mathrm{p}<0.05$.

\section{Results}

This study recruited 92 (40 PMS cases and 52 healthy controls) school going adolescent girls with a mean age of $14 \pm 1$ years from different schools of Karachi, Pakistan. Of the total samples, $43 \%$ were depressed (35\% were mild and $8 \%$ were moderate) while $57 \%$ were normal. The overall distribution of samples was described in Table 1.

Table 1: Study participants' characteristics

\begin{tabular}{|l|c|c|}
\hline Variables & PMS cases & Controls \\
\hline BMI & (n) & (n) \\
\hline Normal (18-25) & & \\
\hline Underweight (<18) & 27 & 42 \\
\hline Overweight (25-30) & 5 & 5 \\
\hline Obesity (> 30) & 1 & 2 \\
\hline
\end{tabular}


Biosight 2020; 01(02): 11-15

\begin{tabular}{|l|c|c|}
\hline W/H ratio & & \\
\hline Acceptable $(<0.85)$ & 34 & 42 \\
\hline Unacceptable $(>0.85)$ & 6 & 10 \\
\hline Menarcheal age & & \\
\hline $12 \_14$ & 31 & 49 \\
\hline$<12$ & 9 & 3 \\
\hline Cycle length & & \\
\hline Normal (3-7) & 2 & 0 \\
\hline Short (1-2) & 36 & 47 \\
\hline Long (>7) & 2 & 5 \\
\hline Cycle Regularity & & \\
\hline Yes & 30 & 45 \\
\hline No & 10 & 7 \\
\hline Dysmenorrhea & & \\
\hline No & 16 & 52 \\
\hline Yes & 24 & 00 \\
\hline Depression & & \\
\hline No & 26 & 25 \\
\hline Mild & 2 & 15 \\
\hline Moderate & 9 \\
\hline Severe & 2 & 3 \\
\hline BMI Basal Metablic & W/H & \\
\hline
\end{tabular}

$\mathrm{BMI}=$ Basal Metabolic Index, W/H ratio= Waist to Hip ratio

HWE showed that BDNF genotyping was significantly deviated $\left(\chi^{2}=9.672\right.$, P-value $\left.=0.00187\right)$ among controls. No association $\left(\chi^{2}=1.685\right.$, $\mathrm{p}$-value $\left.=0.431\right)$ was observed between BDNF genotyping and PMS among menarcheal girls. $\mathrm{AA}(\mathrm{OR}=0.923,95 \% \mathrm{CI}=0.052-16.456)$ and $\mathrm{GA}(\mathrm{OR}=0.711,95 \% \mathrm{CI}=0.043-11.865)$ genotypes of BDNF were found to be protective for PMS (Table 2).

Table 2: Association of BDNF genotyping and PMS among participants

\begin{tabular}{|c|c|c|c|c|c|c|}
\hline Genotype & PMS cases (n) & Controls (n) & Pearson $\chi^{2}$ & P-value & Odd ratios $(95 \% \mathrm{CI})^{*}$ & P-value \\
\hline GG (Val/Val) & 1 & 1 & & & 1 & \\
\hline GA (Val/Met) & 27 & 38 & 1.685 & 0.431 & $0.711(0.043-11.865)$ & 0.812 \\
\hline $\begin{array}{l}\text { AA } \\
\text { (Met/Met) }\end{array}$ & 12 & 13 & & & $0.923(0.052-16.456)$ & 0.957 \\
\hline Total & 40 & 52 & & & & \\
\hline G-allele & 29 & 40 & 0.094 & 0.759 & 1 & \\
\hline A-allele & 51 & 64 & & & $1.099(0.601-2.009)$ & 0.759 \\
\hline Total & 80 & 104 & & & & \\
\hline
\end{tabular}

\section{Discussion}

Premenstrual syndrome (PMS) is a multidimensional disorder affects various physiological systems. Several biological mechanisms that cause PMS have been proposed. Majority of them emphasize on the gonadal steroids, their metabolites and their communications with neurotransmitters and neuro-hormone systems including serotonin, gammaAminobutyric acid (GABA), cholecystokinin (CCK), and the renin-angiotensin-aldosterone system (RAAS). Alterations in the responses of these systems to gonadal steroidal fluctuations during the menstrual cycle of women and increased sensitivity to variations in steroids may be the cause PMS in susceptible females. Homeostatic disruption and poor adaptation may be the basic underlying mechanisms. 


\section{Biosight 2020; 01(02): 11-15}

Our findings suggested that BDNF genotyping deviate significantly in accordance with the Hardy Weinberg principle which is in contrary to other findings [18]. No relationship between BDNF genotyping and PMS was found due to the small sample size. This pilot study first time report the association between PMS and BDNF genotyping which has not been previously testified. However a recent study was done on the plasma variations of BDNF and different phases of menstrual cycle among menstruating women with PMS and suggested that BDNF was found to be significantly lower during luteal phase of the menstrual cycle [10]. Whereas earlier report has determined the increase incidences of depressive episodes and BDNF gene polymorphism [19]. A meta-analysis was conducted on geriatric depression to compare the frequency of BDNF polymorphism among cases and psychiatrically healthy controls which suggested that individual possess Met allele were at increased risk for geriatric depression than Val/Val homozygotes [20]. However, this study is limited to the small sample size. Further research is needed with large sample cohort to confirm the results.

The study concluded that BDNF genotype may not associated the PMS among Pakistani Menarcheal girls.

\section{Authors' contributions}

FN and MI designed the study and directed its implementation, including quality assurance and control. TAK helped supervise the field activities and designed the study's analytic strategy. MI helped to conduct the literature review and prepare the Manuscript.

\section{Ethics approval and consent to participate}

Not applicable.

\section{Human and animal rights}

Not applicable.

\section{Consent for publication}

Not applicable.

\section{Availability of data and materials}

None.

\section{Funding}

None.

\section{Conflict of interest}

The authors declare no conflict of interest, financial or otherwise.

\section{Acknowledgements}

None.

\section{References}

1. Halbreich U, Borenstein J, Pearlstein T, Kahn LS. The prevalence, impairment, impact, and burden of premenstrual dysphoric disorder (PMS/PMDD). Psychoneuroendocrinology 2003; 28 Suppl 3: 1-23.

2. Hofmeister S, Bodden S. Premenstrual Syndrome and Premenstrual Dysphoric Disorder. Am Family Physician 2016; 94(3): 236-40.

3. Tolossa FW, Bekele ML. Prevalence, impacts and medical managements of premenstrual syndrome among female students: cross-sectional study in College of Health Sciences, Mekelle University, Mekelle, northern Ethiopia. BMC women's health 2014; 14: 52.

4. Garg P, Matreja PS, Khosla PP, Kaur L, Mohan P. Correlation of symptoms of premenstrual syndrome in Indian set-up. Am J Health Res 2014; 2(3): 102-5.

5. Direkvand-Moghadam A, Sayehmiri K, Delpisheh A, Kaikhavandi S. Epidemiology of Premenstrual Syndrome (PMS)-A systematic review and meta-analysis study. J Clin Diagnostic Res 2014; 8(2): 106.

6. Tabassum S, Afridi B, Aman Z, Tabassum W, Durrani R. Premenstrual syndrome: Frequency and severity in young college girls. Anxiety 2005; 45(27): 4-5.

7. Dennerstein L, Lehert P, Heinemann K. Global study of women's experiences of premenstrual symptoms and their effects on daily life. Menopause Int 2011; 17(3): 88-95.

8. Bertone-Johnson ER, Hankinson SE, Forger NG, Powers SI, Willett WC, Johnson SR, et al. Plasma 25hydroxyvitamin D and risk of premenstrual syndrome in a prospective cohort study. BMC women's health 2014; 14(1): 56.

9. Oral E, Ozcan H, Kirkan T, Askin S, Gulec M, Aydin N. Luteal serum BDNF and HSP70 levels in women with premenstrual dysphoric disorder. Eur Arch Psychiat Clin Neurosci 2013; 263(8): 685-93. 


\section{Biosight 2020; 01(02): 11-15}

10. Cubeddu A, Bucci F, Giannini A, Russo M, Daino D, Russo N, et al. Brain-derived neurotrophic factor plasma variation during the different phases of the menstrual cycle in women with premenstrual syndrome. Psychoneuroendocrinology 2011; 36(4): 523-30.

11. Merlio J-P, Ernfors P, Jaber M, Persson H. Molecular cloning of rat trkC and distribution of cells expressing messenger RNAs for members of the trk family in the rat central nervous system. Neuroscience 1992; 51(3): 513-32.

12. Bath KG, Lee FS. Variant BDNF (Val66Met) impact on brain structure and function. Cognitive Affective Behav Neurosci 2006; 6(1): 79-85.

13. Aguilera M, Arias B, Wichers M, Barrantes-Vidal N, Moya J, Villa H, et al. Early adversity and 5-HTT/BDNF genes: new evidence of gene-environment interactions on depressive symptoms in a general population. Psychol Med 2009; 39(9): 1425-32.

14. Hosang GM, Shiles C, Tansey KE, McGuffin P, Uher R. Interaction between stress and the BDNF Val66Met polymorphism in depression: a systematic review and meta-analysis. BMC medicine 2014; 12(1): 7.

15. Lau JY, Goldman D, Buzas B, Hodgkinson C, Leibenluft E, Nelson E, et al. BDNF gene polymorphism (Val66Met) predicts amygdala and anterior hippocampus responses to emotional faces in anxious and depressed adolescents. Neuroimage 2010; 53(3): 952-61.

16. Gillings MR. Were there evolutionary advantages to premenstrual syndrome? Evolutionary applications 2014; 7(8): 897-904.

17. Zung WW. A self-rating depression scale. Arch Gen Psychiatry 1965; 12(1): 63-70.

18. Wu JQ, Tan YL, Tan SP, Hui L, Lv MH, Soares JC, et al. Altered BDNF is correlated to cognition impairment in schizophrenia patients with tardive dyskinesia. Psychopharmacology 2015; 232(1): 223-32.

19. Gujral S, Manuck SB, Ferrell RE, Flory JD, Erickson KI. The BDNF Val66Met polymorphism does not moderate the effect of self-reported physical activity on depressive symptoms in midlife. Psychiatry Res 2014; 218(1-2): 93-7.

20. Pei Y, Smith AK, Wang Y, Pan Y, Yang J, Chen Q, et al. The brain-derived neurotrophic-factor (BDNF) val66met polymorphism is associated with geriatric depression: A meta-analysis. Am J Med Genetics Part B: Neuropsychiatric Genet 2012; 159(5): 560-6. 